\title{
Impact of COVID-19 on UK Foundation Doctors: Training and Safety
}

\section{Ben Blackburn ( $\nabla$ b.blackburn1@nhs.net )}

East and North Hertfordshire NHS Trust https://orcid.org/0000-0002-8958-7754

James Thomas Ferryman

East and North Hertfordshire NHS Trust

\section{Adla Alattas}

East and North Hertfordshire NHS Trust

\section{Research article}

Keywords: COVID-19, PPE, training, safety

Posted Date: June 1st, 2020

DOI: https://doi.org/10.21203/rs.3.rs-30834/v1

License: (c) (i) This work is licensed under a Creative Commons Attribution 4.0 International License. Read Full License 


\section{Abstract}

Objective: To survey Foundation doctors on support, training, and guidance received in relation to COVID19 during the pandemic.

Methods: A 24 question digital survey with a mix of open-ended, multiple-choice, and rating-scale questions was distributed to the 18 UK Foundation Schools. Questions established trainee demographics and the quantity of COVID-19 training received; with focused questions relating to personal safety and support for vulnerable individuals.

Results: 714 doctors completed the survey; $55 \%$ in $\mathrm{FY} 2,43 \%$ in $\mathrm{FY} 1$, and $2 \%$ above $\mathrm{FY} 2$ level. $74 \%$ of respondents reported receiving no formal training on COVID-19. Mean confidence was $84 \%$ in diagnosing COVID-19, and $56 \%$ in managing it. $75 \%$ did not receive formal training on the requisite safety precautions for suspected COVID-19 cases. $67 \%$ had not been fit tested and $75 \%$ of those who failed their fit test were not provided with alternative equipment. 30 doctors reported being pregnant and none had received additional support regarding protective measures. 47 doctors reported being immunocompromised and 42 of them had received no additional support in view of their increased risk. $93 \%$ of doctors had not received definitive guidance regarding the impact of this on their ARCP sign-off and progression of training.

Discussion: Alarming proportions of Foundation trainees are not currently being provided with formal training or support for their personal safety during the COVID-19 outbreak. This is remediable through the urgent implementation of formal COVID-19 training, standardised across NHS trusts to ensure a consistent standard of care for the protection of trainees and patients.

\section{Background}

Transmission of a novel coronavirus (SARS-COV2) from China has caused a global pandemic, ${ }^{1,2}$ resulting in an unprecedented burden on healthcare systems worldwide. The virus manifests as a respiratory illness, termed COVID-19. ${ }^{3}$ While many remain asymptomatic, disease severity ranges from mild and moderate disease, to an acute respiratory distress syndrome (ARDS), and those requiring critical care. ${ }^{4}$ Transmission to the UK was confirmed on 31st January 2020,5, 6 with the first death on 5th March $2020 .{ }^{7}$ UK case fatality rates are estimated at $8 \%,{ }^{8}$ with the greatest risk to those with underlying conditions such as cardiorespiratory, renal, or hepatic disease; diabetes; immunocompromise; and/or advanced age (>70). $.9,10,11$ Concerns regarding vertical transmission, risk of miscarriage, and intrauterine death have also been raised; however current evidence remains inconclusive. ${ }^{12}$

Pressure on the NHS increased significantly in the wake of this outbreak; with primary-care, secondarycare, and 111 telephone services facing a surge in demand. NHS Trusts in particular were forced to adapt rapidly to both a rise in overall demand and to the specific care needs of these patients. Significant changes were needed, including workforce reallocation, implementation of training relating to treatment 
and handling of COVID-19 patients; and acquisition of sufficient personal protective equipment (PPE), together with testing for its effectiveness (which can vary between individuals, necessitating alternatives) and training in its use. At present, final year medical and nursing students are being fast-tracked into clinical roles with a recruitment drive for retired NHS professionals currently underway. ${ }^{13}$ Implementation of these changes is ongoing.

Frontline healthcare workers face considerable risk due to the potential for repeated exposure to infected individuals, many of whom may be asymptomatic given the lengthy incubation period of 5-10 days. ${ }^{14}$ PPE and appropriate training are therefore essential in offsetting this burden of risk. The screening process for COVID-19 is limited however, and only some patients presenting with fever or cough are selected. Use of the requisite protections and enhanced precautions is therefore limited, heightening risk of transmission from the asymptomatic population.

With rising incidence, prevalence, and mortality rates, ${ }^{15}$ appropriate training and support is paramount in safeguarding the wellbeing of NHS staff and patients. Foundation doctors are among frontline staff being redeployed to areas of need. ${ }^{16}$ They are a vital resource within the NHS; and are uniquely positioned to support and staff medical teams. This places them at considerable risk compared to other roles, grades, and specialties which are more insulated from the hazards of working with COVID-19.

\section{Methods}

The cross-sectional survey was designed online using the website SurveyMonkey $\odot$. It was distributed to Foundation Doctors across the 18 UK Foundation Schools using official email networks and via exclusive Foundation School social media groups. The survey opened on 15th March 2020 and closed on 23rd March 2020.

24 questions were included, projected to take respondents 7 minutes to complete. Participation was anonymous to maintain confidentiality. The survey consisted of three principal sections. Section 1 included questions to establish key demographics such as trainee grade, foundation school, and department. In section 2 participants were asked to quantify the amount of formal training received in relation to COVID-19 and PPE, and to rate their overall confidence in the diagnosis and management of COVID-19. Section 3 primarily targeted trainees with high risk characteristics such as pregnancy, immunosuppression, and co-morbidities; and assessed the provision of additional support and/or training in relation to these underlying vulnerabilities. Additionally, trainees were asked if they had received definitive guidance on ARCP sign-off.

A combination of open-ended, multiple choice, and rating scale questions were used throughout.

Data was collated and analysed using the built-in software of SurveyMonkey®. Ethical approval was not required for this study. 


\section{Results}

714 doctors answered with 55\% of respondents in Foundation Year 2 (FY2), 42.7\% in Foundation Year 1 (FY1), and 2.3\% above FY2 level. Data was collected from all 18 UK Foundation Schools with the highest response rates in Oxford (140), North Central and East London (101), and Yorkshire and Humber (92). Doctors working in 18 specialties responded, with the highest proportions in general surgery (17.9\%), acute medicine (9.6\%), and emergency medicine (9.1\%).

Hours of COVID-19-specific training varied between foundation schools (Figure 1). 74.1\% reported having received no training, while others had received either 1 hour $(16.2 \%), 2$ hours $(5.6 \%), 3$ hours $(0.7 \%)$, and more than 3 hours of training in $3.4 \%$ of cases. On a confidence scale of 0 to $100 \%$ (complete confidence), mean confidence was 84\% in COVID-19 diagnosis and 56\% in COVID-19 management.

$75.3 \%$ had not received formal training in the requisite safety precautions for encountering individuals with suspected COVID-19. 67.1\% had not been fit tested. 99 respondents failed their fit test; and of these 74 were not provided with alternative equipment. 14 of the 25 respondents provided with alternative equipment received no training in its use.

30 respondents were pregnant and none had received additional support or guidance regarding personal protection. 47 respondents were reported as immunocompromised, and of these 42 denied having received additional support or guidance. 83 respondents reported having significant medical comorbidities and of these 82 had not received additional support or guidance in view of this.

Of 629 respondents with isolation facilities in their trust, 50.5\% reported being unaware of its location(s). $58 \%$ of respondents denied being trained on what actions to take should they develop symptoms of COVID-19 while working in the hospital.

93\% of trainees denied receiving definitive guidance on how this will affect their foundation training and Annual Review of Competence Progression (ARCP) sign-off.

Additional comments provided by respondents were coded and themes were identified. Prevalent themes were issues relating to ARCP and progression of training, concerns regarding personal safety in high risk individuals, and disappointment in not rotating.

\section{Discussion}

This survey gathered responses over a one-week period, thereby minimising data heterogeneity, which may have resulted from changes in training provision as Trusts responded to the evolving circumstances. Similar responses in all domains of the survey from its inception to closure evidence this, enabling analysis of responses collectively. 
Moreover, data included all UK Foundation Schools, reflecting a degree of generalisability to results and the ubiquity of a lack of formal COVID-19 training for Foundation trainees.

The highest response rates were in the specialties most heavily affected, directly or indirectly, by the outbreak - reflecting the most relevant demographics of trainees, namely: acute medicine, emergency medicine, general surgery, elderly care, and intensive care. Notably, trainees working in acute medicine, emergency medicine, and intensive care are exposed to a high COVID-19 caseload; trainees in elderly care risk transmitting infection to extremely vulnerable patients; and in several trusts general surgery juniors are required to cover medical wards to support their colleagues.

The mounting demand on trainees to provide care for a high volume of COVID-19 patients puts both doctors and patients at risk of critical illness. This deepens the need for proper PPE provision and training in its use. The survey reveals a current lack of formal COVID-19 training - particularly with regards to PPE; with insufficient fit testing and provision of alternative PPE for trainees failing their initial fit test. This highlights a need for a formal standardised training programme for Foundation trainees incorporating these elements.

Responses indicate an almost complete lack of proactive identification and support for high-risk trainees; namely immunocompromised, pregnant, and co-morbid individuals. Although guidance for the protection of individuals defined as extremely vulnerable within the general population exists ${ }^{17}$ no such guidance exists for vulnerable Foundation doctors, who are more frequently exposed to COVID-19 than the general population.

Furthermore, a significant proportion of respondents reported a lack of definitive guidance on the implications for ARCP, and potential impact on progression of training. An upper limit of 20 sick-days applies to Foundation doctors in each 12-month period of the Foundation programme. ${ }^{18}$ This has not been amended despite the extenuating circumstances. An increased burden of sickness is anticipated and many doctors have been forced to self-isolate. Trainees are being redeployed with more demanding rotas being imposed; rotas featuring more on-call work and more hours overall. These changes alone are likely to precipitate further sickness absence. These factors will be particularly relevant to those extremely vulnerable individuals required to self-isolate for 12 weeks in accordance with government advice. Definitive guidance on this matter would be of great benefit and is currently awaited.

\section{Conclusions}

The absence of standardised formal training on COVID-19 for Foundation doctors is remediable through the design and implementation of an urgent national training programme. Training must address: diagnosis and management of COVID-19; safe and effective PPE use; mandatory fit testing; and in the event of failed fit tests, provision of suitable alternatives with appropriate training. Trusts should actively screen for vulnerable doctors and provide additional support and guidance, which may take the form of enhanced PPE training; redeployment to lower risk clinical areas; advice on self-isolation; and guidance 
on the impact on Foundation training progression. Greater effort to support, educate, and protect trainees will strengthen the NHS and safeguard its patients in the face of this unprecedented challenge.

\section{Abbreviations}

FY1 - Foundation Year 1

FY2 - Foundation Year 2

ARCP - Annual Review of Competency Progression

PPE - Personal Protective Equipment

ARDS - Acute Respiratory Distress Syndrome

NHS - National Health Service

\section{Declarations}

\section{Ethics approval and consent to participate}

Not applicable - ethical approval was not required for this study. Have used NHS Research and Ethics Committee (REC) tool to confirm that this research does not require REC approval.

\section{Consent for publication}

Not applicable - Manuscript does not contain data of individual persons. As per the UK Data Service this is a large scale survey that does not include any identifiable information and does not require written consent. A consent statement stating that information in survey may be used for research purposes is to be provided to participants in lieu of this.

\section{Availability of data and materials}

The datasets generated during and/ or analysed during the current study are available in the SurveyMonkey repository, https://www.surveymonkey.com/results/SM-LVDFPB7M7/ ${ }^{19}$

\section{Competing Interests}

The authors declare that they have no competing interests

\section{Funding}

N/A

\section{Author's contributions}


Devised idea for study and contributed to design of survey. Distributed survey online. Wrote Abstract, Methods and Discussion section and was a major contributor in editing the Abstract, Background, Methods, Results and Discussion sections for final manuscript.

$\mathrm{JF}$

Contributed to survey design. Wrote Backgrounds section and was a major contributor in editing Abstract, Background, Methods, Results and Discussion sections for final manuscript

AA

Major author in design of survey. Wrote Results section and contributed to final drafts of Abstract, Background, Methods, Results and Discussion sections.

All authors read and approved the final manuscript.

\section{Acknowledgements}

Not applicable.

\section{Authors' Information}

None

Footnotes

None

\section{References}

1. The nCoV Outbreak Joint Field Epidemiology Investigation Team, Qun L. An outbreak of NCIP (2019nCoV) infection in China-Wuhan, Hubei Province, 2019-2020. CCDC Weekly. 2020;2(5):79-80.

2. World Health Organisation. WHO Director-General's opening remarks at the media briefing on COVID19 - 11 March 2020. 11 March 2020. https://www.who.int/dg/speeches/detail/who-director-generals-opening-remarks-at-the-media-briefing-on-covid-19--11-march-2020. Accessed 1 April 2020.

3. Zhu N, Zhang D, Wang W, et al. A novel coronavirus from patients with pneumonia in China, 2019. N Engl J Med. 2020;382:727-773. DOI:10.1056/NEJMoa2001017

4. Yang $X, Y u Y, X u$ J, et al. Clinical course and outcomes of critically ill patients with SARS-CoV-2 pneumonia in Wuhan, China: a single-centered, retrospective, observational study [published online ahead of print 24 February 2020]. Lancet Respir Med. 2020. DOI:10.1016/S2213-2600(20)30079-5. Accessed 1 April 2020. 
5. Ball T, Wace C. Hunt for contacts of coronavirus-stricken pair in York. The Times. 31 January 2020. https://www.thetimes.co.uk/article/hunt-for-contacts-of-coronavirus-stricken-pair-in-york-dh363qf8. Accessed 1 April 2020.

6. Moss $P, B a r l o w ~ G$. Lessons for managing high-consequence infections from first COVID-19 cases in the UK. Lancet. 2020;395(10227):e46. DOI:10.1016/S0140-6736(20)30463-3

7. BBC News. Coronavirus: Woman in 70s becomes first virus fatality in UK. 5 March 2020. https://www.bbc.co.uk/news/uk-51759602. Accessed 1 April 2020.

8. Johns Hopkins Center for Systems Science and Engineering. Coronavirus COVID-19 global cases. 2020.

https://gisanddata.maps.arcgis.com/apps/opsdashboard/index.html\#/bda7594740fd40299423467 48e9ecf6. Accessed 1 April 2020.

9. Wu Z, McGoogan JM. Characteristics of and important lessons from the coronavirus disease 2019 (COVID-19) outbreak in China: summary of a report of 72314 cases from the Chinese Center for Disease Control and Prevention [published online ahead of print 24 February 2020]. JAMA. 2020. DOI:10.1001/jama.2020.2648. Accessed 1 April 2020.

10. Yang J, Zheng Y, Gou X, et al. Prevalence of comorbidities in the novel Wuhan coronavirus (COVID19) infection: a systematic review and meta-analysis [published online ahead of print 12 March 2020]. Int J Infect Dis. 2020. DOI: 10.1016/j.jiji.2020.03.017. Accessed 1 April 2020.

11. Public Health England. Guidance on social distancing for everyone in the UK. 30 March 2020. https://www.gov.uk/government/publications/covid-19-guidance-on-social-distancing-and-forvulnerable-people/guidance-on-social-distancing-for-everyone-in-the-uk-and-protecting-older-peopleand-vulnerable-adults. Accessed 1 April 2020.

12. Yu N, Wei L, Kang Q, Xiong Z, et al. Clinical features and obstetric and neonatal outcomes of pregnant patients with COVID-19 in Wuhan, China: a retrospective, single-centre, descriptive study [published online ahead of print 24 March 2020]. Lancet. 2020. DOI:10.1016/S1473-3099(20)301766. Accessed 1 April 2020.

13. NHS England. Former docs and nurses told "Your NHS Needs You" to tackle greatest global health threat in history. 19 March 2020. https://www.england.nhs.uk/2020/03/former-docs-and-nurses-toldyour-nhs-needs-you-to-tackle-greatest-global-health-threat-in-history/. Accessed 1 April 2020.

14. Lauer S, Grantz K, Bi Q, et al. The Incubation Period of Coronavirus Disease 2019 (COVID-19) From Publicly Reported Confirmed Cases: Estimation and Application [published online ahead of print 10 March 2020]. Ann Intern Med. 2020. DOI:10.7326/M20-0504. Accessed 1 April 2020.

15. European Centre for Disease Prevention and Control. Coronavirus Disease 2019 (COVID-19) Pandemic: Increased Transmission In The EU/EEA And The UK - Seventh Update. 25 March 2020. C Accessed 1 April 2020.

16. General Medical Council. Supporting The Covid-19 Response: Plans For Management Of Medical Training Rotations. 17 March 2020. https://www.gmc-uk.org/news/news-archive/supporting-thecovid-19-response--plans-for-management-of-medical-training-rotations. Accessed 1 April 2020. 
17. Public Health England. Guidance On Shielding And Protecting People Defined On Medical Grounds As Extremely Vulnerable From COVID-19. 30 March 2020.

https://www.gov.uk/government/publications/guidance-on-shielding-and-protecting-extremelyvulnerable-persons-from-covid-19/guidance-on-shielding-and-protecting-extremely-vulnerablepersons-from-covid-19. Accessed 1 April 2020.

18. Health Education England. Annual Review Of Competency Progression (ARCP) Requirement Guidance-2020. 2020. https://foundationprogramme.nhs.uk/covid-19. Accessed 1 April 2020.

19. Blackburn B, Ferryman J, Alattas A. The UK Foundation Trainee COVID-19 Survey data sets. 2020. https://www.surveymonkey.com/results/SM-LVDFPB7M7/. Accessed 15 May 2020

\section{Figures}

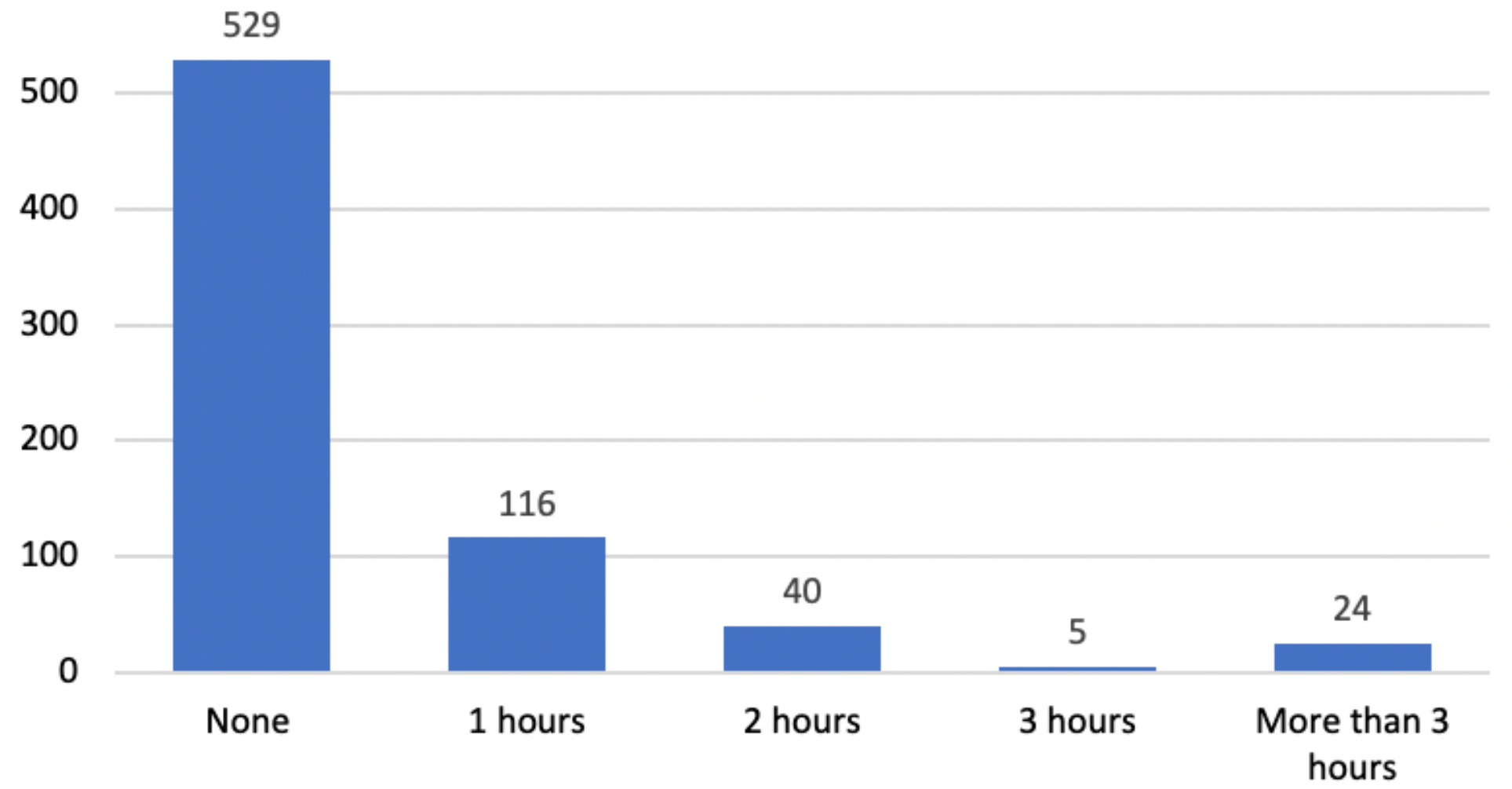

Figure 1

Number of training hours received from foundation schools regarding COVID-19 